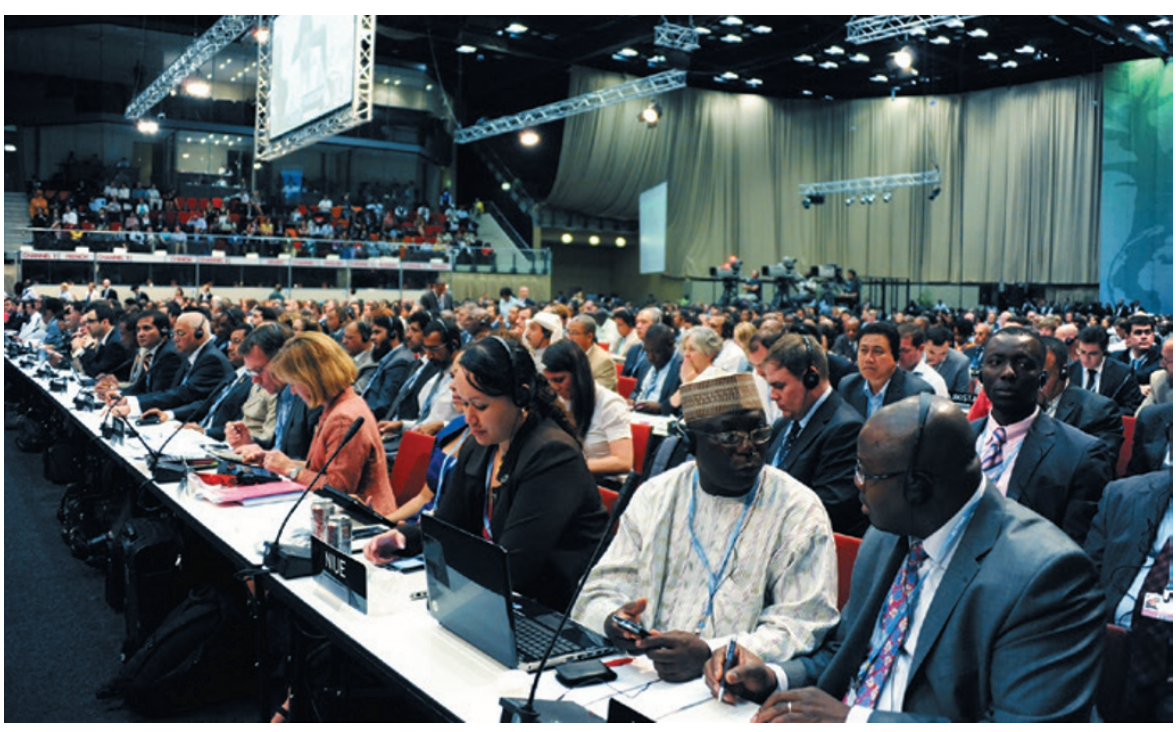

Delegates at the 2011 UN Climate Change Conference in Durban, South Africa.

ENVIRONMENT

\section{Climate stalemate}

\section{Oliver Geden welcomes an analysis of the political inertia impeding a global treaty to limit warming.}

\section{$\mathrm{T}$} his year's climate summit in Paris, starting on 30 November, is a focal point for policymakers, diplomats, political analysts and scientific advisers. Each week of the run-up brings sweeping political declarations and comprehensive reports. Recommendations abound for a global climate treaty to avoid dangerous climate change.

The United Nations Framework Convention on Climate Change (UNFCCC) passed more than 20 years ago, and the Intergovernmental Panel on Climate Change (IPCC) has published 5 assessment reports. Yet there is still no effective regime for emissions reductions and adaptation to climate change.

It is time to consider the workings of international politics to help to explain why the UN has not been able to deliver a comprehensive, ambitious climate treaty. That would rein in expectations for the 21st Conference of the Parties (COP21) in Paris. Such analysis is rare, making Climate Change in World Politics, by international-relations scholar John Vogler, most welcome. Vogler provides a detailed reconstruction of how the international community has dealt with climate change over the past 25 years, and how that has contributed to the current impasse.

The debate on global climate governance has focused more on declarations of intent from key state and non-state actors. Less attention has been given to results delivered by the network of international institutions, centred on the UNFCCC and its various

agreements. In analyses of climate policy, the dominant, 'functionalist' approach looks at forums of international cooperation such as the UNFCCC as if they exist solely to serve collective efforts towards climate solutions. Vogler begs to differ.

He proceeds from two premises. First, sovereign states are still the main determiners of global climate policy, because only they have the necessary regulatory authority. Second, to assess the potential and limits of such policy accurately, it is necessary to consider power politics, prestigeseeking and other behaviours specific to national governments. Vogler rightly assumes that most activi-

"Some key drivers of emissions have been continually exempted from the scope of international climate policy." ties under global climate policy do "not necessarily accord" with the stated purpose of mitigation and adaptation. Regional conflicts or the formation of factions, such as the Group of 77 (G-77) caucus of developing countries, can lead to long-lasting coalitions. In the G-77, development policy generally trumps climate policy. And for a long time, emerging economies such as Brazil and China continued to present themselves as developing countries, effectively avoiding mitigation commitments. State governments are also driven by
Climate Change in World Politics JOHN VOGLER Palgrave Macmillan 2015.

short-term economic interests, aimed at maintaining domestic political power.

So although govern ments like to tout their problem-solving capabilities, their approach is often more vague: one of 'dealing with problems' Vogler shows that there were many competing definitions of climate change even before the UNFCCC was passed. And he reveals how some of the principles that define the climate regime gained widespread acceptance - for instance, the focus on territorial emissions and the principle that industrialized countries have the greatest responsibility for mitigation. He also shows how some key drivers of emissions (population growth and globalized trade flows in particular) have been continually exempted from the scope of international climate policy.

At the same time, the fragmented portfolio of themes covered by the climate regime (for example, environmental justice, carbon markets and climate refugees) has emerged from struggles for power. Governments wage these battles through complicated procedural rules and selective perceptions of climate research. This can be seen, for instance, in the variable interpretations of cumulative historical emissions of industrialized countries and emerging economies.

Vogler pinpoints other reasons for pessimism about COP21. Many countries - notably the United States and China - have no interest in an effective top-down regime or the strong international institutions needed to prevent dangerous climate change. No deal will be reached in Paris that will make it possible to limit the increase in global temperatures to $2^{\circ} \mathrm{C}$ above preindustrial levels, even though this was the goal of the Durban Platform for Enhanced Action, decided at COP17 in 2011.

The emerging climate regime, with nationally determined mitigation at its core, does mark a shift towards respect for the global power structure. Nevertheless, COP2 1 is likely to confirm the modus operandi of UN climate policy. That is: "kicking the can down the road in order to delay potentially difficult and costly decisions".

Vogler's intention is not to indict the key actors in climate policy, nor to accuse them of a lack of political will. His aim is to warn against unrealistic expectations of the problem-solving capacity of such a complex and fragmented form of policy coordination. Already, such expectations have led to disillusionment and threaten a rejection of the entire process.

Oliver Geden is head of the European Union Research Division at the German Institute for International and Security Affairs (SWP) in Berlin.

e-mail: oliver.geden@swp-berlin.org 